\title{
Inhalt des 28. Bandes
}

\section{Heft 1}

Shvartsburg, A. B., Geometrical Optics in Non-Linear Wave Theory. . . . . . . . . . 1 Kalinkin, B. N., Cherbu, A. V., and B. L. Shmonin, Space-Time Approach to the Description of Cumulative-Type Processes

\section{Heft 2}

Matsumoto, H., Semenoff, G., Tachiki, M., and H. Umezawa, Quantum Electrodynamics in Solids . . . . . . . . . . . . . . . . . . . . . . . . . . . . . . 67

Lazo-Tueve, D., and W. RüHL, Invariant Forms of the Lorentz Group . . . . . . . . . 99

\section{Heft 3}

Biebl, K. J., Kuein, M., and R. NAhNhader, A Jet Model Study of Correlations in Hadron-

Hadron Reactions Due to Resonance Production . . . . . . . . . . . . . . . . . . 123

\section{Heft 4}

Grib, A. A., Mamayev, S. G., and V. M. Mostepanenko, Vacuum Stress-Energy Tensor and Particle Creation in Isotropic Cosmological Models . . . . . . . . . . . . . . . . . 173 Schwarz, F., An Approximation Scheme for Constructing $\pi^{0} \pi^{0}$ Amplitudes from ACU Requirements . . . . . . . . . . . . . . . . . . . . 201

\section{Heft 5}

Frscher, J., and E. ŚáLY, The Pomeranschuk Theorem and Its Modifications . . . . . . . 237 Ldkierski, J., Field Operator for Unstable Particle and Complex Mass Description in Local QFT . . . . . . . . . . . . . . . . . . . . . . . . 259 Moylan, P., Fiber Bundles in Non-Relativistic Quantum Mechanics. . . . . . . . . . . 269

\section{Heft 6}

NovaK, M. M., Interactions of Photons with Electrons in Dielectric Media. . . . . . . . . 285

\section{Heft 7}

Fusco-Girard, M., Mancini, F., and M. Marinaro, Electrodynamics of Superconductors as a Consequence of Local Gauge Invariance . . . . . . . . . . . . . . . . . . . . . 355 


\section{Heft $8 / 9$}

Barbashov, B. M., and V. V. Nesterenko, Differential Geometry and Nonlinear Field Models . . . . . . . . . . . . . . . . . . . . . . . . . . . . . . . 427

KAZAKov, D. I., and D. V. ShIRkov, Asymptotic Series of Quantum Field Theory and Th-ir

Summation . . . . . . . . . . . . . . . . . . . . . . 465

\section{Heft 10}

Darbaidze, Ya. Z., Esakia, S. M., Garsevanishvili, V. R., and Z. R. Menteshashvili,

Problems of Deep Inelastic Lepton-Nucleus Interaction . . . . . . . . . . . . . 501 Grassberger, P., The Gribov Process: Soft Parton Interactions in So-called Reggeon Field

Theory . . . . . . . . . . . . . . . . . . . . . . . . . . . . 526

Grassberger, P., and M. Scheunert, Fock-Space Methods for Identical Classical Objects . 547

\section{Heft 11}

LeinaAs, J. M., Topological Charges in Gauge Theories . . . . . . . . . . . . . . . . 579

\section{Heft 12}

PAUL, H., The Einstein Podolsky Rosen Paradox and Local Hidden-Variables Theories . . . 633 


\section{FORTSCHRITTE DER}

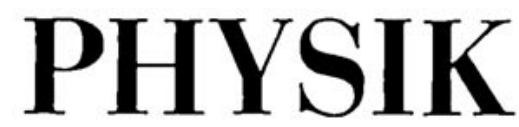

HERAUSGEGEBEN IM AUFTRAGE DER PHYSIKALISCHEN GESELLSCHAFT DER

DEUTSCHEN DEMOKRATISCHEN REPUBLIK

VON F. KASCHIUHN, A. LÖSCHE, R. RITSCHL UND R. ROMPE

HEFT $1 \cdot 1980 \cdot$ BAND 28

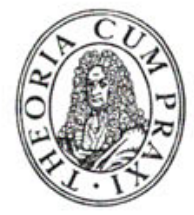

A K A D E M I E - V E R L A G • B E R L I N

EVP 10,- M 